\title{
Serological Markers and/or Intestinal Biopsies in the Case-finding of Celiac Disease
}

\author{
Aaron Lerner ${ }^{1}$, Sandra Neidhöfer ${ }^{2}$, Torsten Matthias ${ }^{2}$ \\ ${ }^{1}$ Pediatric Gastroenterology and Nutrition Unit, Carmel Medical Center, B. Rappaport School of Medicine, Technion-Israel Institute of \\ Technology, Haifa, Israel \\ ${ }^{2}$ Aesku.Kipp Institute, Wendelsheim, Germany \\ *Corresponding author: aaronlerner1948@gmail.com
}

Received May 10, 2015; Revised May 12, 2015; Accepted May 23, 2015

\begin{abstract}
The new 2012 ESPGHAN guidelines for the pediatric diagnosis of celiac disease (CD) unraveled and stimulated an old/new discussion on the most efficient case- finding in pediatric CD. The fine balance between reliable serological markers and the gold diagnostic standard of small bowel histology is somewhat better understood. Due to a low diagnostic rate, changes in phenotype, increased incidence, epidemiological shifts, importance of early implementation of gluten free diet to prevent complications, the case-finding of CD should be improved. Our adult gastrointestinal colleagues did not adopt ESPGHAN diagnostic criteria and within the pediatric gastroenterology community, controversies exist. The present editorial on pediatric $\mathrm{CD}$ complements an adult $\mathrm{CD}$ one. It expands on the drawbacks, limitations and criticisms of the guidelines and calls for prudency, further research and follow-up studies. Until recent observations are implemented in the future guidelines, small bowel histology should remain the gold standard for case-finding in CD.
\end{abstract}

Keywords: celiac disease, case-finding, diagnosis, serology, intestinal biopsy, children

Cite This Article: Aaron Lerner, Sandra Neidhöfer, and Torsten Matthias, "Serological Markers and/or Intestinal Biopsies in the Case-finding of Celiac Disease.” International Journal of Celiac Disease, vol. 3, no. 2 (2015): 53-55. doi: 10.12691/ijcd-3-2-7.

\section{Introduction}

Why should case-finding of $\mathrm{CD}$ be improved?

It is generally accepted that CD affects $1 \%$ of western populations, whereby northern countries like Sweden, Finland and Ireland the incidence is higher. One exception is the Sahara desert region in North Africa with an incidence of 5.6\%. Even in the Far East, where rice is the main staple food, increased incidence of CD is being reported. Currently, we are witnessing a diffused ongoing epidemic of CD of great scale. Epidemiological data provides strong evidence of a steady rise in celiac disease throughout westernized societies over the last six decades [1]. The reasons for this worldwide surge in CD incidenceare debatable.

Table 1. summarizes the suggested explanation for $\mathrm{CD}$ incidence expansion

\begin{tabular}{|l|c|}
\hline Potential reasons & references \\
\hline Increased wheat intake: & \\
-Increased production and consumption of wheat & {$[2]$} \\
-Higher gluten content in modern wheat & {$[3]$} \\
\hline Increased influence of environmental inducers of CD: & \\
-Infections & {$[4]$} \\
-Stress & {$[5]$} \\
-Gastrointestinal microbiome alterations=dysbiosis & {$[6]$} \\
\hline Increased intestinal permeability by food industrial additives & {$[2,7]$} \\
\hline Increased public and professional awareness & {$[8,9]$} \\
\hline Improved tools for diagnosis & {$[10]$} \\
\hline Genetic advantage and survival of CD patients & {$[3,11]$} \\
\hline
\end{tabular}

In addition to the increased incidence, the ratio between diagnosed/undiagnosed CD is substantial, ranging between1-2/8-9, respectively. Key reasons for this are the epidemiological and phenotypical shifts taking place in the disease. It has been shown that the classic intestinal clinical picture of malnutrition, chronic diarrhea and nutritional deficiencies are disappearing and extraintestinal presentations are emerging. Skin, endocrine, skeletal, hepatic, hematological, thrombophilic, gynecological, fertility-related, dental, obesity and behavioral abnormalities are often described. Today, we are witnessing an epidemiological shift in the disease phenotype toward a more advanced age, and increased prevalence of latent, hyposymptomatic or asymptomatic behavior [12]. All these changes make the diagnosis of the disease more difficult and the reliance on symptomatology more remote [13]. These are some of the reasons why serological screening and diagnosis of CD have achieved prime importance. Finally, upon diagnosis, $C D$ is a treatable disease and implementation of a GFD can prevent many complications and extraintestinal manifestations of the disease including: hematological and gastrointestinal malignancies, osteoporosis/penia, decreased height, malnutrition and nutritional deficiencies, fertility impairment, stillbirth, dysmaturity, psychosocial retardation, impairment of quality of life, increased mortality and additional autoimmune associated conditions. Thus, early diagnosis and subsequent adherence to a gluten-free diet is highly recommended. 
These are the main reasons why we need to improve our case-finding strategies in CD.

\section{Case-finding Strategies}

There are currently three main strategies for casefinding: serology, HLA-DQ2/8 typing or intestinal biopsy histology - or any combination of these three. An additional debate is whether to screen normal/high risk asymptomatic/only symptomatic populations or to perform intestinal biopsy on each upper endoscopy.

According to the recent criteria for the diagnosis of childhood celiac disease, published by ESPGHAN in 2012, there is a definite distinction between symptomatic and asymptomatic children [14]. Only symptomatic children with positive HLA-DQ2/8, that mount anti-tTg IgA antibody levels 10 times above the upper normal limit and have positive EMA IgA, are exempt from small bowel biopsy.

These new diagnostic criteria have not been adopted by the different adult gastroenterological associations worldwide [15].

Since implementation of the new ESPGHAN diagnostic flow-charts, substantial experience has been gained and both complimentary [16] and critical [17] publications have appeared. Emerging data are continuously being generated and no doubt will impact future diagnosis algorithms [18].

\section{Bias in ESPGHAN CD Diagnosis Guidelines}

The main criticisms of the 2012 ESPGHAN guidelines cover the following aspects:

1. A more precise definition of "symptomatic" children is needed due to the multifaceted phenotype and the continuous clinical pattern changes [19].

2. Lack of serological markers standardization and relative definitions of the upper limit of normal cut-off levels.

3. Lack of more extended, multicenter data on the optimal multiplication times of the upper limit of normal cut-off, to be used [20,21].

4. The subjectivity and inter-observer variability of the anti-endomysial antibodies.

5. Lack of availability and insurance coverage of HLADQ determination, at least in the developing countries.

6. Lack of standardization of HLA-DQ determination methodology and reporting of its dosage zygosity. An improvement, was recently suggested by the Australasian group [22]

7. By omitting intestinal biopsies, considered as the gold diagnostic standard, CD research might be jeopardized.

8. Lack of adherence to and/or understanding of the guidelines, even by subspecialists [23].

9. Lack of comparison of $\mathrm{CD}$ additional specific autoantibodies to challenge IgA-tTg premiership in the guidelines, for example with the neo-epitope tTg [24-29]. Recent observations show that the tTg neo-epitope outperformst $\operatorname{Tg}[30,31,32]$ and also a combination test including IgA and IgG isoforms [1]. Adding an additional autoantibody can detect Marsh 3 intestinal damage among subjects with moderate anti-tTg levels [33].

10. Not taking into account additional HLA or the multiple non-HLA genes associated with CD. It is foreseeable that a combination of these may improve CD diagnosis, as has recently been suggested [34].

11. None of the CD associated dysbiosis or individual's microbiota, is taken into account. In fact, CD dysbiosis correlates to clinical manifestation, even with a strict GFD, and is determined by the HLA-DQ2 status [35,36,37]

12. None of the evolving epigenetic, transcriptomics, proteomics, and metabolomics of the microbiome or the intestinal compartments' data have been incorporated.

\section{Conclusions}

In summary, the 2012 ESPGHAN guidelines took the professional communities a step forward in CD diagnostic guidelines, but many aspects of these guidelines are incomplete and deserve further evaluation and discussion. Based on the above mentioned arguments [38], and with full respect to the honorable members of the ESPGHAN's CD interest group, it is our personal opinion, that omitting intestinal biopsy is premature. We share Freeman HJ. opinion that a case-finding of CD should, for the time being, include the most cost effective serology, substantiated by adequate small intestinal mucosal biopsies. The subject of serological mass screening of general populations or asymptomatic family members needs further large randomized trials, as suggested recently $[39,40]$.

\section{References}

[1] Lerner A. Serological Diagnosis of Celiac Disease -Moving Beyond the Tip of the Iceberg. International Journal of Celiac Disease. 2014;2:64-66.

[2] Lerner A, Matthias T. Changes in intestinal tight junction permeability associated with industrial food additives explain the rising incidence of autoimmune disease. Autoimmun Reviews. 2015;14:479-89.

[3] Lerner A. The last two millennias eco-catastrophes are the driving forces for the potential genetic advantage mechanisms in celiac disease. Med Hypotheses. 2011;77:773-6.

[4] Lerner A, Reif S. Nonnutritional environmental factors associated with celiac disease: the infectome. In: Shoenfeld Y, Rose N, eds. Infection and Autoimmunity. 2nd ed. San Diego: Elsevier B.V; 2015:829-835.

[5] Ciacci C, Siniscalchi M, Bucci C, Zingone F, Morra I, Iovino, P. Life events and the onset of celiac disease from a patient's perspective. Nutrients. 2013;5:3388-98.

[6] Rostami Nejad M, Ishaq S, Al Dulaimi D, Zali MR, Rostami, K. The role of infectious mediators and gut microbiome in the pathogenesis of celiac disease. Arch. Iran Med. 2015;18:244-9.

[7] Lerner A, Matthias T. Increased consumption of food industry bacterial transglutaminase may explain the surge in celiac disease incidence. Nutr Reviews, In press, 2015.

[8] Aziz I, Karajeh MA, Zilkha J, Tubman E, Fowles C, Sanders DS. Change in awareness of gluten-related disorders among chefs and the general public in the UK: a 10-year follow-up study. Eur J Gastroenterol Hepatol. 2014;26:1228-33.

[9] Zipser RD, Farid M, Baisch D, Patel B, Patel D. Physician awareness of celiac disease: a need for further education. J Gen Intern Med. 2005;20:644-6.

[10] Catassi C, Kryszak D, Louis-Jacques O, Duerksen DR, Hill I, Crowe SE, et al. Detection of Celiac disease in primary care: a multicenter case-finding study in North America. Am J Gastroenterol. 2007;102:1454-60. 
[11] Lerner A. Balanced polymorphism: a survival advantage in celiac disease. Editorial. Medical Hypotheses. 2011;77:1-2.

[12] Lerner A, Agmon-Levin N, Shapira Y, Gilburd B, Reuter S, Lavi I, Shoenfeld Y. The thrombophilic network of autoantibodies in celiac disease. BMC Med. 2013; 11: 89-95.

[13] Katz KD, Rashtak S, Lahr BD et al. Screening for celiac disease in a North American population: sequential serology and gastrointestinal symptoms. Amer J Gastroentrol. 2011;106:13331339.

[14] Husby S, Koletzko S, Korponay-Szabó IR et al. European Society for Pediatric Gastroenterology, Hepatology, and Nutrition guidelines for the diagnosis of coeliac disease. J Pediatr Gastroenterol Nutr. 2012;54:136-60.

[15] Freeman HJ. Small intestinal mucosal biopsies for case-finding in celiac disease. Internat J Cel Dis. 2015;3:50-52.

[16] Mubarak A, Wolters VM, Gmelig-Meyling FH, Ten Kate FJ, Houwen RH. Tissue transglutaminase levels above $100 \mathrm{U} / \mathrm{mL}$ and celiac disease: a prospective study. World J Gastroenterol. 2012;18:4399-403.

[17] Schirru E, Jores RD, Congia M. Prudence is necessary in the application of the new ESPGHAN criteria for celiac disease omitting duodenal biopsy: a case report.Eur J Gastroenterol Hepatol. 2014;26:679-80.

[18] Zevit N, Shamir R. Diagnosis of celiac disease: where are we heading after the ESPGHAN 2012 guidelines? J Pediatr Gastroenterol Nutr. 2014;59 Suppl 1:S13-5.

[19] Garampazzi A, Rapa A, Mura S et al. Clinical pattern of celiac disease is still changing. J Pediatr Gastroenterol Nutr. 2007;45:611-4.

[20] Barak M., Rozenberg O., Froom P., Grinberg M., Reginashvili D., Henig C., Pacht A., Lerner A. Challenging our serological algorithm for celiac disease (CD) diagnosis by the ESPGHAN guidelines. Clin Chem Lab Med. 2013;51;e257-259.

[21] Vermeersch P, Geboes K, Mariën G, Hoffman I, Hiele M, Bossuyt $\mathrm{X}$. Defining thresholds of antibody levels improves diagnosis of celiac disease. Clin Gastroenterol Hepatol. 2013;11:398-403

[22] Tye-Din JA, Cameron DJ, Daveson AJ, Day AS, Dellsperger P, Hogan $C$ et al. Appropriate clinical use of human leukocyte antigen typing for coeliac disease: an Australasian perspective. Intern Med J. 2015;45:441-50.

[23] Atherton R, Ross A, Jessop F, Williams R, Heuschkel R, Zilbauer $\mathrm{M}$. Coeliac disease in children with type 1 diabetes: are current guidelines proving difficult to implement in practice? J Pediatr Gastroenterol Nutr. 2014;59:600-3.

[24] Bizzaro N., Tozzoli R., Villalta D., Fabris M., Tonutti E. Cuttingedge issues in celiac disease and in gluten intolerance. Clin Rev Allergy Immunol. 2012; 42:279-87.

[25] Tozzoli R., Kodermaz G., Tampoia M., Visentini D., Tonutti E., Bizzaro N. [detection of autoantibodies specific for transglutaminase-gliadin peptides complex: a new way to explore the celiac iceberg.] It J Lab Med. 2010; 6; 28-35.

[26] Matthias T., Pfeiffer S., Selmi C., Eric Gershwin M. Diagnostic challenges in celiac disease and the role of the tissue transglutaminase-neo-epitope. Clin Rev Allergy Immunol.2010;38:298-301.

[27] Remes-Troche JM, Ramírez-Iglesias MT, Rubio-Tapia A. Alonso-Ramos A., Velazquez A., Uscanga LF. Celiac disease could be a frequent disease in Mexico: prevalence of tissue transglutaminase antibody in healthy blood donors. J Clin Gastroenterol. 2006;40:697-700.

[28] Rozenberg O., Lerner A., Pacht A., Grinberg M., Reginashvili D., Henig C., Barak M.A new algorithm for the diagnosis of celiac disease. Cell Mol Immunol.2011; 8:146-9.

[29] Remes-Troche JM, Rios-Vaca A., Ramírez-Iglesias MT, RubioTapia A., Andrade-Zarate V., Rodríguez-Vallejo F., LópezMaldonado F., Gomez-Perez FJ, Uscanga LF. High prevalence of celiac disease in Mexican Mestizo adults with type 1 diabetes mellitus. J Clin Gastroenterol.2008; 42:460-5.

[30] Rozenberg O, Lerner A, Pacht A, Grinberg M, Reginashvili D, Henig C, Barak M. A novel algorithm for the diagnosis of celiac disease and a comprehensive review of celiac disease diagnostics. Clin Rev Allergy Immunol. 2012;42:331-41.

[31] Matthias T., Jeremias P., Neidhöfer S., Lerner A. Antibodies against neo-epitope tTg complexed to gliadin are more reliable then anti-tTg for the diagnosis of pediatric celiac disease. $49^{\text {th }}$ ESPGHAN congress, Amsterdam 6-9 th May, 2015.

[32] Matthias T., Jeremias P., Neidhöfer S., LernerA. Comparison of the reliability of celiac disease serology to reflect intestinal damage. 49th ESPGHAN congress, Amsterdam 6-9 $9^{\text {th }}$ May, 2015.

[33] Schirru E, Danjou F, Cicotto L, Rossino R, Macis MD, Lampis R et al. Anti-actin IgA antibodies identify celiac disease patients with a Marsh 3 intestinal damage among subjects with moderate anti-TG2 levels. Biomed Res Int. 2013;2013:630463.

[34] Romanos J, Rosén A, Kumar V, Trynka G, Franke L, Szperl A, et al. Improving coeliac disease risk prediction by testing non-HLA variants additional to HLA variants. Gut. 2014;63:415-22.

[35] Wacklin P, Kaukinen K, Tuovinen E, Collin P, Lindfors K, Partanen J, et al. The duodenal microbiota composition of adult celiac disease patients is associated with the clinical manifestation of the disease. Inflamm Bowel Dis. 2013;19:934-41.

[36] Wacklin P, Laurikka P, Lindfors K, Collin P, Salmi T, Lähdeaho $\mathrm{ML}$, et al. Altered duodenal microbiota composition in celiac disease patients suffering from persistent symptoms on a longterm gluten-free diet. Am J Gastroenterol. 2014;109:1933-41.

[37] Olivares M, Neef A, Castillejo G, Palma GD, Varea V, Capilla A, et al. The HLA-DQ2 genotype selects for early intestinal microbiota composition in infants at high risk of developing coeliac disease. Gut. 2015;64:406-17.

[38] Lerner A, Jeremias P, Matthias T. The world incidence of celiac disease is increasing: a review. Internat. J. OF Recent Scient. Res. In press ,2015.

[39] Kurppa K, Paavola A, Collin P, Sievänen H, Laurila K, Huhtala H, et al. Benefits of a gluten-free diet for asymptomatic patients with serologic markers of celiac disease. Gastroenterology. 2014;147:610-617.

[40] Leffler DA, Kelly CP. The cost of a loaf of bread in symptomless celiac disease. Gastroenterology. 2014;147:557-9. 